\title{
As crônicas de João do Rio e o ensino da história*
}

Magali Gouveia Engel ${ }^{* *}$

\section{RESUMO}

0 artigo trata das possibilidades da utilização das crônicas de João do Rio (1881-1921) para o estudo das relações de trabalho e da problemática da dominação/submissão no contexto de implantação do capitalismo no Brasil. Trata-se de refletir sobre o uso de fontes literárias (em especial de crônicas) no processo de ensino/aprendizagem da história.

Palavras-chave:: crônicas, ensino de história, trabalho, cidade, dominação/ submissão.

$\Lambda$ análise aqui apresentada orienta-se no sentido de refletir sobre as possibilidades de utilização das crônicas de João Paulo Emílio Cristóvão dos Santos Barreto (1881-1921) - o famoso "João do Rio" - produzidas nas duas primeiras décadas do século XX, para o estudo das relações de trabalho e da problemática da dominação/submissão no ensino/aprendizagem da história.

A primeira questão que gostaria de colocar refere-se às razões que podem nos levar a utilizar textos literários para ensinar e aprender história, o que, aliás, não é nenhuma novidade. A literatura pode ser um meio rico e eficaz para construirmos com nossos alunos uma história viva que efetivamente rompa com a velha, mas infelizmente ainda bastante corrente, imagem da história como um saber inútil e chato. Outro aspecto fundamental diz respeito

* Este artigo apresenta alguns resultados parciais da pesquisa intitulada "Trabalho, relações de gêneros e questĩo racial: memórias da cidade através das crônicas (RJ, 1870-1930)", que conta atualmente com o apoio do CNPq. Participam da segunda etapa do projeto os bolsistas do PIBIC Daniel Angelim, Leonardo Ayres Padilha e Leandro Rosetti de Almeida. A versão original do texto foi apresentada no IV Encontro Estadual de Ensino de História e Ciências Humanas realizado na UFF em abril de 2003.

". Professora do Departamento de História da UFF e do Departamento de Ciências Humanas da Faculdade de Formação de Professores da UERJ. 
às possibilidades de aprimoramento da aprendizagem da leitura e da escrita, abrindo-se perspectivas para a construção de parcerias com a área de português e fazendo da disciplina história um lugar também responsável pelo aprofundamento e consolidação do processo de alfabetização dos alunos.

Como veremos mais adiante 0 uso da literatura favorece, ainda, amplas possibilidades de trabalhos interdisciplinares não apenas com a disciplina de português, mas com outras como geografia, ciências, etc.

Mas para utilizarmos a literatura no processo de construção do conhecimento histórico - seja ele em que nível for - é preciso que explicitemos claramente os referenciais teórico-metodológicos que nos guiam. Como qualquer outra fonte, os registros literárioṣ (contos, romances, crônicas, poesias) são produzidos historicamente e, portanto, como argumentam muito bem Sidney Chalhoub e Leonardo Pereira, cabe ao historiador inseri-los "no movimento da sociedade, investigar as suas redes de interlocução social", elucidar, enfim, o modo como elaboram ou expressam "a sua relação com a realidade social" (CHALHOUB e PEREIRA, 1998 : 7), sempre presente, mesmo quando não explicitada. Obras de ficção, mas nem por isso isentas de uma determinada lógica social, cuja identificação e interpretação são pressupostos indissociáveis da análise histórica. Para ler com os olhos da história os registros literários é preciso, pois, reconhecer que o historiador é aquele "capaz de formular uma problemática e de construir uma interpretação em que reconhece o encontro de duas historicidades: a sua própria e a da documentação que utiliza" (NEVES, 1985: 34-35).

É preciso também refletir sobre as especificidades do gênero literário que escollhi. Situadas nas interseções entre a ficção e a realidade, as crônicas são fontes ricas e atraentes para a história em suas mais diversas dimensões. Tecidas no cotidiano da vida revelam-se muitas vezes mais coloridas e dinâmicas do que os textos dos livros didáticos ou de outros tipos de fontes. Através de uma linguagem mais enxuta que dialoga com os leitores de forma direta e objetiva, as crônicas falam de um dia a dia, que mesmo que distante, pode revelar

1 Concebendo-se aqui alfabetização nos termos propostos por Paulo Freire, ou seja, como aprendizagem da leitura do mundo e compreensão do seu contexto. Como bem observou por exemplo Ana Maria Monteiro, "Ensinar a ler nấo é tarefa exclusiva do professor de Português. Não se aprende a ler em um ano, mas ao longo da vida" (MONTEIRO, 2001: 26). 
alguma coisa em comum com o nosso tempo, ao procurar dar conta das dimensöes mais triviais do vivido. Por todas estas razões os registros feitos pelos cronistas se trabalhados de forma criativa e consistente podem seduzir nossos alunos, fazendo-os conceber a história como um saber que diz respeito a todos nós. Vejamos agora algumas possibilidades de se trabalhar com crônicas de Joẫo do Rio no ensino/aprendizagem da história da cidade.

O primeiro passo é apresentarmos nosso autor². João Paulo Emílio Cristóvão dos Santos Barreto nasceu na cidade do Rio no dia 5 de agosto de 1881 - antes, portanto, da abolição da escravidão $0^{3}$. Era filho de Alfredo Coelho Barreto que, apesar de proveniente de uma família importante do Rio Grande do Sul, precisava ensinar matemática na Escola Normal e no Ginásio Nacional (antigo Colégio de Pedro II) para sobreviver. Florência Cristóvão dos Santos Barreto, mãe de João do Rio, era mulata, filha do Dr. Joaquim C. dos Santos médico da Santa Casa de Misericórdia - e de Gabriela Amália Caldeira.

João do Rio foi aluno do colégio do Mosteiro de São Bento e, a partir de 1896, do Ginásio Nacional, ambos freqüentados pelos filhos das elites cariocas. Em 1902, apesar de sua formação não conseguiu ingressar na carreira diplomática por ser "mulato e excessivamente afeminado", segundo a avaliação do Barão do Rio Branco, na ocasião Ministro das Relações Exteriores ${ }^{4}$. Assim, decidiu-se pela carreira jornalística que já havia iniciado em 1899, aos dezoito anos, quando começou a trabalhar no diário "Cidade do Rio", de propriedade de um dos líderes abolicionistas. José do Patrocínio. Em 1903 passou a atuar na Gazeta de Notícias, um dos mais importantes jornais daquela época, onde começou a usar o pseudônimo "João do Rio". Neste periódico publicou as famosas reportagens sobre "As religiões do Rio" (1904) - que depois virariam um livro - e também as entrevistas sobre literatura com quase todos os grandes escritores brasileiros vivos da época (1905) - transformadas em um livro em 1907 - que o conduziriam, em 1910, à Academia Brasileira de Letras, com apenas trinta anos de idade.

2 Os dados biográficos apresentados a seguir foram extraídos de RODRIGUES (1981) e RODRIGUES (1994).

3 Aqui poderíanos aproveitar a oportunidade para recordar com a turma as características fundamentais da sociedade brassileira na últimá década da escravidão e do processo que levou à Abolição em 13 de maio de 1888, curando João do Rio contava com pouco mais de seis anos de idade.

4 É uma ótima oportunidade para trabalhar com os alunos a questão dos preconceitos, especialmente o racial e o sexual, sondando-os sobre o que pensam das discriminações; se conhecem alguém que, como João do Rio, tenha sido prejudicado em sua vida profissional por preconceitos deste tipo; etc. 
Embora muito controvertido, tornou-se um jomalista bastante conhecido e um escritor de sucesso, tendo quase todos os seus livros publicados pela Garnier, a mais poderosa editora da época. Mesmo tendo escrito peças teatrais, romances e conferências, joão do Rio se destacá, sobretudo, na produção de crônicase reportagens e de contos. Aliás, ambos os gêneros já marcados por características dos dizeres modernos $s^{5}$ apresentam profundas semelhanças sob a pena do escritor.

Profundamente inspirado pela obra do escritor irlandês Oscar Wilde (1854-1900)6 , João do Rio ligou-se à corrente literária que se nutria esteticamente da degradaç̃̃o social, moral e política - fruto dos padrões de modernidade excludente característicos do desenvolvimento urbano em bases capitalistas. Assim, a cidade do Rio seria o cenário privilegiado dos seus escritos. Mas que cidade era essa em fins do século XIX e inícios do século XX?

Desde a década de 1870 o Rio que era então corte do Império brasileiro, começava a ser alvo de uma série de projetos de reforma que visavam transformar 0 perfil colonial e atrasado da cidade, transformando-a em uma metrópole moderna e civilizada de acordo com os padrões burgueses. Alguns destes projetos foram efetivados ainda durante a vigência do regime monárquico - como, por exemplo, a transformação do Campo de Santana (ou Praça da República) em um espaço ajardinado inspirado nos modelos dos parques urbanos europeus?. Em 1889, o Rio de Janeiro passou à condição de capital republicana e a implementaçã̃o de reformas

\footnotetext{
5 Para um questionamento dos marcos tradicionais do modernismo brasileiro, vejam-se, por exemplo, os trabalhos de MORAES (1983) e VELLOSO (1996). Uma parceria com aulas de literatura voltadas para a caracterização e a discussão da relação entre modernidade e produção literária seria extremamente frutífera.

6 Adepto do esteticismo, Oscar Wilde defendia a perspectiva da arte pela arte. Criticou com aguda ironia as convenções sociais burguesas da Inglaterra vitoriana. Apesar de muito controvertido, fez bastante sucesso como dramaturgo e escritor. Acusado de práticas homossexuais, foi processado pelo pai de seu jovem discípulo Alfred Douglas e condenado a dois anos de prisão (de 1895 a 1897). Entre seus mais famosos escritos está o romance "O retrato de Dorian Gray" (1891), traduzido por João do Rio e publicado no jornal carioca "A Noite", em 1911.

7 Seria interessante desenvolver um trabalho com os alunos, através do qual eles pudessem visualizar o que era o Campo de Santana antes do ajardinamento (vejam-se gravuras reproduzidas em COARACY, 1965) e comparar com o que é hoje. Questões como, por exemplo: a) porque os diversos nomes que o Campo teve em função de fatos políticos ali ocorridos - Campo da Aclamação, por ter sido palco da Aclamação de Pedro I como Imperador Constitucional do Brasil; Campo da Honra por ter sido o local das manifestações que levaram à abdicação de Pedro I; Praça da República, por ter sido palco da proclamação do novo regime nunca pegaram, permanecendo até hoje a designação tradicional e popular que remete à existência ali da Igreja de Santana? b) quais teriam sido os possíveis significados sociais e políticos que tentaram "civilizar" de acordo com padrões europeus um dos espaços mais populares da cidade do Rio? Para o encaminhamento da discussĩo veja-se, por exemplo, ABREU (1999)
} 
urbanas ganha dimensões mais amplas ${ }^{8}$, chegando a um primeiro momento de apogeu com as reformas do período do presidente Rodrigues Alves (1902-1906) e do prefeito Pereira Passos (1903-1906).

Através do movimento que ficou conhecido como "Bota-Abaixo", os governos federal e municipal abriram largas avenidas - no estilo dos boulevards parisienses, como, por exemplo, a Rodrigues Alves, a Francisco Bicalho, a Central (atual Rio Branco) e a Beira-Mar -, alargaram várias ruas dos bairros centrais da cidade, modernizaram o Porto, etc. Para facilitar o escoamento das mercadorias, higienizar e embelezar os espaços públicos de acordo com os padrões burgueses, as "picaretas do progresso" destruíram espaços onde as classes trabalhadoras da cidade moravam, trabalhavam, se divertiam, enfim sobreviviam em todos os sentidos (NEVES e HEIZER, 1991; CHALHOUB, 1996) ${ }^{9}$. Como consequiência agravou-se o problema habitacional, fazendo com que parte dos trabalhadores tivesse que se deslocar para os subúrbios passando a despender mais tempo e dinheiro para se deslocarem de suas residências para seus locais de trabalho - e a outra parte permanecesse nas regiões centrais da cidade superlotando os cortiços, as casas de cômodo, as hospedarias ou povoando as primeiras favelas surgidas exatamente neste contexto. Assim, os benefícios do progresso favoreciam apenas aos interesses dominantes e agravavam ainda mais as péssimas condições de vida da população trabalhadora ${ }^{10}$.

Alguns escritores eram defensores entusiasmados do tipo de modernidade que estava sendo construída "de cima para baixo". É o caso por exemplo de Olavo Bilac (1865-1918) ${ }^{11}$ que numa crônica publicada em março de 1904 descreve a obra de demolição das ruas centrais da cidade do Rio:

8 Pode-se trabalhar aqui com o exemplo da destruição do cortiço "Cabeça de Porco" - que inspirou um dos mais importantes romances naturalistas brasileiros, 0 Cortiço de Aluísio Azevedo -, em 26 de janeiro de 1893, noticiada em toda imprensa carioca (por exemplo, Gazeta de Notícias, 27 e 28/01). Os professores de história e de português poderiam desenvolver atividades conjuntas a partir do romance e das notícias.

9 Para situar os alunos no contexto das reformas urbanas pode-se utilizar a foto do canteiro de obras durante a construção da Avenida Central, feita por Malta, em 1904 ou 1905, reproduzida, por exemplo, em NEVES E HEIZER (1991:59).

${ }^{10}$ No que se refere a estes aspectos poderia ser bastante produtivo propor uma discussão com os alunos acerca das condições de vida das classes trabalhadoras em meio ao processo de industrialização, utilizando o exemplo da cidade do Rio, através das fotos de habitações populares reproduzidas, por exemplo, em CHALHOUB (1996).

${ }^{11}$ Foi uma das maiores expressões da poesia parnesiana do período - eleito em 1913 "Príncipe dos Poetas Brasileiros" em concurso realizado pela revista Fon! Fon?- e também um importante cronista, tendo assumido o lugar de Machado de Assis, na coluna da Gazeta de Notícias. 
No aluir das paredes, no ruir das pedras, no esfarelar do barro, havia um longo gemido. Era o gemido soturno e lamentoso do Passado, do Atraso, do Opróbio. A cidade colonial, imunda, retrógrada, emperrada nas suas velhas tradições, estava soluçando no soluçar daqueles apodrecidos materiais que desabavam. Mas o hino claro das picaretas abafava esse protesto impotente. Com que alegria cantavam elas - as picaretas regeneradoras! (apud SEVCENKO, 1983:31).

O tempo era de fato um tempo de profundas mudanças na sociedade brasileira: a escravidão havia sido extinta, a república derrubou a monarquia, 0 as inovações tecnológicas capitalistas invadiam o dia-a-dia das pessoas redimensionando o tempo - que passava a andar cada vez mais rápido, ritmado pelo apito das fábricas que iam povoando a paisagem urbana. A cidade do Rio adquiria em alguns de seus espaços as feições de metrópole moderna e civilizada segundo os valores burgueses.

Enquanto isso, procurava-se ocultar o máximo possivel o alto preço deste progresso (usufruído por pouquíssimos) pago pela maioria da população urbana, composta pelas classes trabalhadoras. Mas os segmentos sociais explorados não ficaram "bestializados" diante das estratégias de controle que vinham sendo implementadas pelas administrações republicanas. Lutaram por seus valores, crenças, modos de vida, enfim pela sua sobrevivência de diversas formas, entre elas destacaramse a Revolta da Vacina (1904), os quebra-quebras cada vez mais comuns no cotidiano da cidade ${ }^{2}$ e as greves operárias. Contrariando posturas como a assumida por Olavo Bilac, João do Rio e Lima Barreto (1881-1922) ${ }^{13}$, por exemplo, denunciaram o conteúdo excludente e hierarquizador das mudanças implementadas "de cima para baixo" à medida que a estrutura da sociedade brasileira assumia paulatinamente formas burguesas.

12 Segundo Sevcenko, os quebra-lampiões tornaram-se cada vez mais freqüentes a partir de 1904 . Tais manifestações, "não paravam somente no sistema de iluminação pública, praticamente tudo era alvo do impulso destrutivo: bondes, carroças, carruagens, vitrines, estabelecimentos comerciais, casas particulares, o calçamento das ruas, os trilhos, os relógios e os bancos" (SEVCENKO, 1983:66). Trata-se de uma ótima oportunidade para discutir o conteúdo político deste tipo de manifestação, nos termos propostos por Edward Thompson quando reflete sobre os motins de fome na Inglaterra do século XVIII (THOMPSON, 1998).

13 Afonso Henriques de Lima Barreto foi um dos maiores escritos brasileiros. Fez de toda sua produção literária, uma missão, pois acreditava que através da literatura seria possível construir uma sociedade mais justa e solidária. Em seus romances, contos, memórias e crônicas denunciou e combateu todas as formas de discriminação e de dominação da sociedade brasileira. 
No conjunto de sua obra, João do Rio esboçou as múltiplas, complexas e contraditórias feições da capital republicana. A miséria em suas dimensões econômico-sociais, mas também morais, produto do projeto de modernidade imposto pelas elites dirigentes brasileiras figura entre as temáticas mais marcantes na abordagem do autor. 0 olhar do cronista seria, contudo, bastante ambíguo, pois se de um lado, como assinalou Antonio Candido, revela-se um observador capaz de "denunciar a sociedade com um senso de justiça e uma coragem lúcida que não encontramos nos que se diziam adeptos ou simpatizantes do socialismo e do anarquismo..." (CANDIDO, 1980 : 89), por outro, João do Rio associava a miserabilidade dos despossuídos à periculosidade, alimentando o estigma que estabelece a correspondência entre classes pobres e classes perigosas (CHALHOUB, 1996).

Antes de começarmos a trabalhar os textos escolhidos é preciso estimular uma reflexão dos alunos sobre o que caracteriza o gênero crônica em parceria com o professor de português. Poderíamos partir, por exemplo, como sugere um artigo de Margarida de Souza Neves (NEVES, 1995), de questões colocadas por cronistas contemporâneos: "Crônicas, que são? Pretextos ou testemunhos?" (José Saramago apud NEVES, 1995) ou "Crônica é um relato, é uma conversa, é um resumo de um estado de espírito?" (Clarice Lispector apud NEVES, 1995). A busca das muitas possiveis respostas pode ser estimulada com uma pesquisa das crônicas publicadas nos jornais atuais, através da qual os alunos certamente nos ajudarão a não enveredarmos "pelo perigoso e tentador caminho das definições e das classificações, sempre demasiado estreitas para abarcar a riqueza deste gênero polimórfico..." (NEVES, 1995 : 17) ${ }^{14}$. Desde que, evidentemente, saibamos não apenas ouvir, mas também aproveitar efetivamente o que eles trouxerem como resultado da atividade proposta (CHIAPPINI, 2002).

0 próximo passo será apresentar aos alunos o (s) texto (s) selecionado (s) que no nosso caso são as duas crônicas de João do Rio: "Os trabalhadores de estiva" e "A fome negra", publicadas originalmente na Gazeta de Notícias em junho de 1904, e que depois integraram a coletânea de textos sobre tipos e

\footnotetext{
${ }^{14}$ Para enriquecer o debate poderíamos fazer uma leitura com os alunos do delicioso texto de Antonio Candido, "A vida ao rés-do-chão" (CANDIDO, 1992), onde o autor nos ensina a gostar de crônicas. A partir das discussões delinearíamos, juntamente com os alunos, o perfil da crônica moderna - consolidada a partir de finais do século XIX - em sua diversidade e complexidade.
} 
profissões das ruas cariocas, intitulada A alma encantadora das ruas, publicada pela primeira vez em $1908^{15}$. A primeira descreve um dia de trabalho dos estivadores do cais da cidade do Rio e a segunda, narra a pesada jornada dos trabalhadores da pedreira e dos depósitos de manganês e de carvão da Ilha da Conceição (Niterói). Ambas são produzidas a partir das observações e entrevistas feitas pelo autor nas visitas que fez aos dois locais. Esta é uma das marcas características da produção literária de joão do Rio, seguindo a inspiração de Baudelaire ${ }^{16}$, segundo a qual o papel do artista moderno era o de vivenciar a comunhão entre a cidade e o povo.

Antes de pedirmos que os alunos façam uma primeira leitura dos dois textos, é importante situar o que podemos neles apreender. Os fatos objetivos são descritos sob a ótica do autor, submetendo-os a um filtro, cujo foco expressa seus valores, suas crenças, suas posições políticas, enfim o seu lugar social. Assim, os textos podem esclarecer a visão do autor sobre o mundo onde viveu que por mais excepcionais que possam ser sempre expressarão concepções e práticas coletivas e possíveis naquele tempo e lugar, porque históricas. Mas podem também, nos revelar dimensões objetivas da realidade social a qual se referem direta ou indiretamente. É preciso considerar ainda que a leitura que fazemos dos textos (seja de que tipo forem) também é produzida a partir das lentes produzidas pelo lugar sócio-cultural (econômico, político, ideológico, etc.) que ocupamos na sociedade.

Depois de realizadas várias leituras dos texios ${ }^{17} \mathrm{~A}$ leitura pode ser precedida da discussão de questões, como por exemplo: a) o que é estivador? b) o que imaginam que fazem os trabalhadores na pedreira e nos depósitos de manganês

${ }^{15}$ A maioria das crônicas e reportagens reunidas neste livro foi primeiramente publicada na Gazeta de Notícias e as demais na revista Kosmos. Utilizamos aqui a edição de 1987.

${ }^{16}$ Poeta e crítico de arte, Charles Pierre Baudelaire foi um dos mais importantes literatos do seu tempo. Precursor do simbolismo teve também grande influência sobre o modernismo do século XX. Abordando temas que oscilam entre o sublime e o escabroso, fez de sua estética uma poderosa arma contra as convenções morais que caracterizavam a sociedade burguesa da França oitocentista.

${ }^{17}$ A leitura pode ser precedida da discussão de questões, como por exemplo: a) o que é estivador? b) o que imaginam que fazem os trabalhadores na pedreira e nos depósitos de manganês e carvão? c) sabem onde fica o cais da cidade do Rio? E a Il ha da Conceição? Ao professor de português caberia aprofundar um pouco a relação entre a cidade e o poeta/escritor moderno, usando a estratégia que achar mais conveniente e atrativa. A finalidade da sugestão é a de discutir e sistematizar elementos considerados fundamentais para introduzir a leitura das crônicas. 
e carvão? c) sabem onde fica o cais da cidade do Rio? E a Ilha da Conceição? Ao professor de português caberia aprofundar um pouco a relação entre a cidade e o poeta/escritor moderno, usando a estratégia que achar mais conveniente e atrativa. A finalidade da sugestãa é a de discutir e sistematizar elementos considerados fundamentais para introduzir a leitura das crônicas., através das quais possam ser levantadas e discutidas, em conjunto, as dúvidas; pesquisados os significados das palavras; formulados e debatidos os comentários dos alunos sobre os textos, seria importante ampliarmos o caráter interdisciplinar e/ou multidisciplinar do trabalho que estamos propondo: A área de geografia, por exemplo, poderia aproveitar as crônicas para estudar o mapa das ilhas da baía da Guanabara, localizando junto com os alunos as que são mencionadas por João do Rio (Bárbaras e da Conceição) e situando suas atividades econômicas. Em ambas havia depósitos de manganês que "a Inglaterra cada vez mais compra ao Brasil" e que "vem de Minas até a Marítima em estrada de ferro" ("A fome negra", JOÃO DO RIO, 1987:114). Pode-se, portanto estudar a produção e comercialização de minérios e de carvão, as principais áreas brasileiras produtoras, a importância destas matérias-primas para a indústria; o papel das ferrovias para transportá-las até os portos, as transformações da paisagem provocadas pelas atividades de exploração de minérios e de extração/ produção de carvão, etc., sem que se fique necessariamente preso à época abordada pelo escritor.

O diálogo com os professores de ciências ou de biologia e química tornase fundamental para enriquecer os debates e, portanto, para ampliar as possibilidades de aproveitamento dos potenciais dos textos. Assim seria bastante produtivo que trabalhassem com os alunos as características e propriedades químicas do manganês e do carvão. $\mathrm{E}$, ainda, como podem ser processados e utilizados como matéria-prima e na geração de energia, mas, também quais as consequiências ecológicas de sua extração e/ou produção e como podem atuar na saúde dos trabalhadores responsáveis pela sua exploração e pelo seu transporte. As reflexões daí decorrentes podem se estender para os dias atuais, estimulando debates em torno de questões cruciais - por exemplo, como conciliar desenvolvimento tecnológico e preservação da natureza?

Especificamente sob a ótica da história, a problemática central que norteia as crônicas escolhidas refere-se às relações de trabalho nas pedreiras, nos 
depósitos de carvão e de manganês na Ilha da Conceição e na estiva. Em torno dela podemos sugerir uma série de questões, a partir das quais é possivel refletir com os alunos sobre temas fundamentais da história da sociedade brasileira nas últimas décadas do século XIX e nas primeiras do XX. A análise da crônica "A fome negra", por exemplo, pode contribuir para a discussão do caráter das relações de trabalho juridicamente livres disseminadas nas cidades (e também nos campos) após a abolição da escravidão. Segundo João do Rio, na pedreira e nos depósitos de manganês e de carvão da Ilha da Conceição, "trabalha-se dez horas por dia, com pequenos intervalos para as refeições, e ganha-se cinco mil réis. Há, além disso, o desconto da comida, do barracão onde dormem, mil e quinhentos..." ("A fome negra", JOÃO DO RIO, 1987:114). Estes trabalhadores podem dispor livremente de seus salários? É possível caracterizar este tipo de exploração do trabalho como tipicamente capitalista? ${ }^{\text {?. . . }}$

0 significado da liberdade efetivamente desfrutada por estes trabalhadores pode ser apreendido através das imagens que os situam na condição de prisioneiros de uma engrenagem que os engolia: "Uma vez apanhados pelo mecanismo de aços, ferros e carne humana, uma vez utensílio apropriado ao andamento da máquina, tornam-se autômatos com a teimosia de objetos movidos a vapor" (JOÃo DO RIO, 1987:114). Até mesmo o desfrute do direito de ir e vir era extremamente reduzido: "Há homens que, dois anos depois de desembarcar, nunca pisaram no Rio e outros que, passando quase uma existência na ilha, voltaram para terra com algum dinheiro e a certeza da morte" (JOÃo DO RIO, 1987:114). Por fim, há, ainda a referência ao Correia, o feitor, responsável pelo ritmo e pela disciplina do trabalho na ilha da Conceição. Apesar de característica do universo escravista, a figura do feitor continuará desempenhando um papel ativo nas mais diversas práticas de expropriação do trabalho, inclusive nas que caracterizariam o processo produtivo das primeiras fábricas.

De acordo com João do Rio a maioria dos trabalhadores dos depósitos de manganês e de carvão e da pedreira da Ilha de Conceição eram de origem espanhola e, sobretudo, portuguesa e apenas alguns eram "homens de cor". 0 texto abre, pois, perspectivas interessantes para o estudo do papel dos imigrantes

\footnotetext{
${ }^{18}$ Poder-se-ia aproveitar esta oportunidade para situar e discutir as diversas relações de trabalho não capitalistas que permanecem ou surgem a partir da desagregação das relações de produção escravistas, mas que contribuem para viabilizar a construção do capitalismo no Brasil (MARTINS, 1979).
} 
de origem européia e dos libertos e livres de origem africana nos setores econômicos sobre os quais se construiria a sociedade capitalista brasileira. Na crônica "Os trabalhadores de estiva", o autor refere-se à crescente presença do "elemento brasileiro" no processo de organização das associações dos estivadores. Mercado de trabalho disputadíssimo, certamente a estiva foi um dos palcos dos muitos embates que, travestidos de significados étnicos/raciais ou nacionalistas, expressavam também a luta pelo acesso aos restritos meios de sobrevivência (CHALHOUB, 1986; RIBEIRO, 1990).

o surgimento e as características históricas do movimento operário, especialmente as especificidades que este assumiria na cidade do Rio é outro ponto que pode ser explorado a partir da crônica sobre os trabalhadores da estiva, onde 0 autor menciona a organização das associações operárias e cita 0 exemplo da União dos Operários Estivadores. Através de manifestações e greves, os trabalhadores da estiva reivindicavam seus direitos: "Que querem eles? Apenas ser considerados homens dignificados pelo esforço e a diminuição das horas de trabalho, para descansar e para viver" (JOÃO DO RIO, 1987:110). Os fundamentos ideológicos que buscavam legitimar a repressão às manifestações e greves dos trabalhadores também são alvo das reflexões do cronista. Assim, por exemplo, opõe-se à ótica da polícia que definia os estivadores ém greve como "criaturas ferozes", qualificando-os como "resignados", "desiludidos" e "angustiados". Mas, se tal caracterização pode funcionar como elemento de legitimação da resistência, ao mesmo tempo e contraditoriamente, minimiza ou até anula a capacidade destes trabalhadores se revoltarem contra as condições de trabalho e de vida às quais eram submetidos. A tensão entre a imagem da resignação, do conformismo e da inevitável submissão dos trabalhadores e 0 reconhecimento da capacidade efetiva ou potencial de se revoltarem é recorrente em ambas as crônicas. As ambigüidades do posicionamento de João do Rio podem estimular uma reflexão junto aos alunos em torno da complexa relação entre submissão, negociação e conflito e a atuação dos trabalhadores como agentes da história, capazes de resistir à dominação por meio das mais diversas estratégias e de transformar a realidade em que vivem (THOMPSON, 1998).

Além disto, se por um lado, João do Rio rejeita a qualificação dos trabalhadores como "feras", em função de sua suposta rebeldia, por outro, atribui ao trabalho físico a capacidade de animalizar e/ou reificar os homens. 
Entende o escritor que as condições escorchantes às quais eram submetidos os trabalhadores explorados pelo capital embrutecia-os tornando-os incapazes intelectualmente. Neste sentido, em "A fome negra", os trabalhadores são caracterizados em seu discurso como "manada de homens"; "feras de uma ménagerie"; "seres embrutecidos" e "incapazes de ter idéias" que "não têm nervos, têm molas; não têm cérebros, têm músculos hipertofiados". Os estivadores eram seres que ligados aos guinchos, "eram parte da máquina; agiam inconscientemente". Trata-se, pois, de colocar em discussão tais concepções, estimulando-se os alunos a refletirem: será que quem trabalha com os músculos deixa de pensar?

Enfim, as condições de trabalho na Ilha da Conceição ("A fome negra") e no cais do Rio de Janeiro ("Os trabalhadores de estiva") são objeto de descrições detalhadas e densas, capazes de situar nossos alunos no universo do trabalho que marcou o advento de uma sociedade burguesa no Brasil das primeiras décadas do século XX. Neste sentido, seria interessante propor uma reflexão em torno das mudanças e continuidades históricas que vêem marcando o processo de construção e consolidação do capitalismo no Brasil, levantando questões do tipo: na sua opinião ainda existem no Brasil trabalhadores que se submetem a condiçôes de trabalho semelhantes às descritas por João do Rio?

A análise das duas crônicas selecionadas e as discussões por elas suscitadas podem, portanto nos levar a um estudo mais profundo, mas também mais dinâmico e interessante das características históricas do início do processo de industrialização no Brasil, destacando-se suas especificidades no que se refere às relações de produção, à importância do setor terciário, etc., tomando-se como exemplo a cidade do Rio (nesta época principal centro industrial do Brasil). Os mecanismos de expropriação do trabalho pelo capital, as estratégias de dominação, as contradições em tomo das qualificações do trabalho - que no âmbito da ideologia burguesa dignifica o homem elevando-o à condição de cidadão, mas que na lógica que busca legitimar a dominação animaliza e reifica o trabalhador braçal excluindo-o da cidadania -, as estratégias de submissão e de resistência dos trabalhadores - que mesmo sem levar a rupturas e transformações radicais, fazem deles sujeitos da história, restringindo e redefinindo os termos da dominação capitalista - são alguns dos muitos pontos que podem ser desenvolvidos a partir das crônicas de João do Rio aqui examinadas. 
Bibliografia

Abreu, Martha, O Império do Divino, RJ, Nova Fronteira; SP, FAPESP, 1999.

Candido, Antonio, "Radicais de ocasião", Teresina etc., RJ, Paz e Terra, 1980, pp. 83-94. , "A vida ao rés-do-chão", em Antonio Candido e outros, A Crônica: o gênero, sua fixação e suas transformações no Brasil, Campinas, Ed. Unicamp; RJ, FCRB, 1992.

Coaracy, Vivaldo, Memórias da cidade do Rio de Janeiro, RJ, José Olympio, 1965.

Challoub, Sidney, Cidade febril, SP, Cia das Letras, 1996.

,Trabalho, lar e botequim, SP, Brasiliense, 1986.

Chalhoub, Sidney e Pereira, Leonardo A. de M., "Introdução", em Chalhoub, Sidney e Pereira, Leonardo Affonso de M. (org.), A bistória contada: capítulos de História Social da Literatura no Brasil, Rio de janeiro, Nova Fronteira, 1998.

Chiappini, Ligia, Aprender e ensinar com textos de alunos, SP, Cortez, 2002 ( $5^{\mathrm{a}} \mathrm{ed}$.).

Martins, José de S., O cativeiro da terra, SP, Liv. Ed. Ciências Humanas, 1979.

Monteiro, Ana M., "Ensino de História: das dificuldades e possibilidades de um fazer, em Davies, N. (org.), Para além dos conteúdos no ensino de bistórici, RJ, Acess, 2001, pp. $17-31$.

Moraes, Eduardo J. de, "A constituição da idéia de modernidade no modernismo brasileiro", RJ, UFRJ, 1983 (tese de doutorado).

Neves, Margarida de S., "O bordado de um tempo (A História na estória de Esaú e Jacó)", Revista Tempo Brasileiro, RJ, n.81, 32-42, abr-jun. 1985.

"História da crônica. Crônica da história", em Beatriz Resende (org.), Cronisias do Rio, Rio de Janeiro, José Olympio/ CCBB, 1995, pp. 15-31.

Neves, M. de S. e Heizer, A., A ordem é o progresso, SP, Arual, 1991.

Ribeiro, Gladys S., Mata galegos: os portugueses e os conflitos de trabalho na República Velha, SP, Brasiliense, 1990.

Rio, João do, A alma encantadora das ruas, RJ, Sec.Mun.de Cult., Dep. Geral de Doc. e Inf. Cult., 1987.

Rodrigues, Antonio E. Martins, João do Rio: a cidade e o poeta - o olhar de flâneur na belle époque tropical, RJ, Ed. FGV, 2000. 
Rodrigues, João Carlos, João do Rio: catálogo bibliográfico, Rio de Janeiro, Sec, Mun. Cult., DGDIC, Div. Ed., 1994.

Sevcenko, Nicolau, Literatura como missão: tensões sociais e criação cultural na Primeira República, São Paulo, Brasiliense, 1983.

Thompson, E. P., Costumes em comum: estudos sobre a cultura popular tradicional, São Paulo, Cia. das Letras, 1998.

Velloso, Mônica Pimenta, Modernismo no Rio de Janeiro: Turunas e Quixotes, Rio de janeiro, Ed. FGV, 1996.

\section{JOAO DO RIO'S chronicles and the history reaching}

\section{ABSTRACT}

The article delineates the possibilities of using the chronicles written by João do Rio (1881-1921) in order to study labor relations and the problematics of domination/subordination in the context of the implementation of capitalism in Brazil. In it, we reflect upon the uses of literary sources (and chronicles in particular) in the teaching and learning of history.

Key words: chronicles, history teaching, labor relations, city, domination/ subordination 